\title{
Political Stasis or Protectionist Rut? Policy Mechanisms for Trade Reform in a Democracy*
}

\author{
Emily Blanchard ${ }^{\dagger} \quad$ Gerald Willmann ${ }^{\ddagger}$
}

November 12, 2007

\section{Comments Welcome}

\begin{abstract}
This paper analyzes the dynamics of trade policy reform under democracy. In an overlapping generations model, heterogeneous agents may acquire skills when young thereby determining the skill composition of their cohort. Current and anticipated trade policies influence education decisions and thus the identity of the median voter. We show that there may exist two political steady states: one protectionist and one liberal. Transition from the former to the latter can be achieved by government announcements, temporary educational subsidies, or tariff liberalization by trading partners, but generally not by transfer payments to adversely affected workers. We find additionally that reform is politically feasible only if the proposed liberalization is sufficiently large, suggesting that radical reform may be necessary for escaping a protectionist political rut.
\end{abstract}

Keywords: Dynamic Political Economy, Trade Policy, Skill Acquisition, Politically Stable Policy Paths, Referenda

JEL Classifications: D72, E60, F13, F16

\footnotetext{
${ }^{*}$ We are grateful to colleagues and seminar participants for helpful comments and discussions. Funding from the Bankard Fund for Political Economy is gratefully acknowledged.

${ }^{\dagger}$ Department of Economics, University of Virginia, P.O. Box 400182, Charlottesville, VA 22904-4182; ph. (01) 434.924.3607; blanchard@virginia.edu.

${ }^{\ddagger}$ Department of Economics, Catholic University of Leuven, Naamsestraat 69, 3000 Leuven, Belgium; gerald.willmann@econ.kuleuven.be.
} 


\section{Introduction}

The political process of trade liberalization is inherently dynamic, the path to reform characterized by difficult and often unpopular labor market adjustments that may give rise to political foot dragging or backsliding. In the presence of populist voter pressure, proposed liberalization programs that commence with great fanfare and optimism may easily (and frequently do) succumb to public backlash. In democratic political environments - which necessarily are subject to constant legislative reevaluation - generational differences, evolving expectations, and individual workers' abilities to adapt to changing market conditions surely are paramount in determining the ultimate success or failure of liberalization efforts.

It is surprising, then, that most theoretical accounts of endogenous trade policy limit themselves to static models. ${ }^{1}$ Our paper takes a new modelling approach to highlight the potential importance of voters' future expectations and intergenerational differences in a dynamic political economy model while maintaining a parsimonious analytical structure customary to the trade literature. We develop a two period overlapping generations (OLG) model with endogenous skill acquisition in which agents vote every period on a referendum to adjust the current trade policy or to maintain the status quo. When deciding whether to acquire skills, heterogenous agents within each generational cohort take into account current and expected trade policies. The model exhibits a feedback mechanism in which trade policy determines the skill composition of the population, and hence the identity of the median voter, who in turn votes on trade policy.

In the policy referendum, voters choose between two economic states of the world, a relatively protectionist regime or its more liberal counterpart. Given the population's skill composition at the time of the vote and the expected trade regime in the future, we find the potential for multiple political steady states, which are defined as economic equilibria under which the median voter would elect to maintain the status quo trade policy. The

\footnotetext{
${ }^{1}$ An important empirical exception is a recent paper by Magee, Davidson, and Matusz (2005), who examine the relationship between labor market characteristics and measures of voters' trade preferences. Their paper convincingly articulates a connection between dynamic trade adjustment costs and U.S. congressional campaign contributions, but stops short of developing a formal model.
} 
multiplicity of equilibria obtains because the existing policy regime affects not only the skill acquisition choices of the young generation, but also the identity of the median voter. The more protectionist the existing policy, the greater the unskilled proportion of the older generation (which unambiguously opposes reform), and thus the lower the relative skill level of the median voter among her younger (pivotal) cohort. Intuitively, status quo trade policy enjoys the power of hysteresis through the past skill acquisition decisions of the older generation. $^{2}$

When the model generates multiple political steady states, voters may get stuck in a "protectionist rut" even though the country as a whole would be better off under the more liberal regime, itself a politically sustainable equilibrium. ${ }^{3}$ Given that there are efficiency gains from freer trade, transition from the relatively protectionist regime to a more liberal policy should be feasible. We show that transition can be achieved by credible policy announcements as well as temporary educational subsidies that tilt the balance towards the more liberal policy path. Traditional trade adjustment assistance through temporary transfer payments, on the other hand, will be counter-productive if the compensation scheme adversely affects workers' skill acquisition decisions. We find moreover that the political feasibility of transition increases in the magnitude of the tariff liberalization, and also in the presence of "reciprocal" reforms by trading partners. Radical policy proposals and multilateral liberalization agreements thus may be more likely to be approved than small or unilateral reforms.

Our approach and results - though novel to the trade literature - are motivated in part by recent work in macroeconomics. In particular, our approach is similar to that in Hassler, Rodríguez Mora, Storesletten, and Zilibotti (2003) who analyze domestic redistributive

\footnotetext{
${ }^{2}$ This feature of our model complements Fernandez and Rodrik (1991), who demonstrated the potential for "status quo bias" in the presence of voter uncertainty about their future gains or losses from proposed reform. Our model generates the same result under perfect foresight through political interaction across generations.

${ }^{3}$ This finding is reminiscent of Basu and Van (1998), who demonstrate the potential for multiple equilibria in the context of child labor; when children work, adult wages may be sufficiently low that households need to send children to work to make ends meet, but when children do not work, adult wages may be high enough (because of labor shortages) that parents can afford not to send their children to work.
} 
policies, and relates to quantitative models by Bassetto (1999), Saint Paul (2001), Krusell and Ríos-Rull (1996), and Krusell, Quadrini, and Ríos-Rull (1996). These authors find, as we do, the potential for multiple equilibria, and the Hassler, Rodríguez Mora, Storesletten, and Zilibotti (2003) model in particular shares the feature that the identity of the current constituency supporting a proposed policy depends on the current policy framework. Ortega (2004) uses a similar approach to analyze the nexus between immigration policy and redistribution, yet skill acquisition is entirely stochastic in his model. Earlier papers that feature a feedback loop between public policy and individual behavior include Glomm and Ravikumar (1995), Saint Paul and Verdier (1997), and Benabou (2000). Our model differs from this earlier work in a number of important dimensions; perhaps most notably, intergenerational political frictions in voting are a key element in our model, whereas previous studies assume that the young do not vote, so that the median voter does not have a stake in the future economy. ${ }^{4}$

Though inspired by innovations in dynamic political economy, the present paper relates closely to a wide body of the trade literature. Our model is reminiscent of both the two-period model in Staiger and Tabellini (1987) who analyze the time consistency of trade policy, and also Maggi and Rodríquez-Clare (1998) and Maggi and Rodríguez-Clare (2006) who consider the trade policy effects of sunk investment - in their case by forward looking firms rather than by short lived workers as in our model. In the same spirit as our work, McLaren (2002) warns of the potential for welfare reducing endogenous policy lock-in in a multi-country setting with preferential trade liberalization. Most recently, Krishna and Mitra (2006) develop a two country median voter model of endogenous trade liberalization; their setting is static, however, and so does not give rise to multiple political equilibria in a unilateral context as ours does. Related in their emphasis on the interaction between worker heterogeneity and trade costs are the careful analyses by Yeaple (2005) and Ohnsorge and Trefler (2004), though both of these papers consider a static framework in which trade policy is exogenous.

\footnotetext{
${ }^{4}$ In giving suffrage to the young generation, our model both highlights the role of intergenerational voting blocks and permits a number of interesting and relevant extensions, such as differential voter turnout across generations or population growth.
} 
A number of important contributions to the trade literature feature an OLG setup but stop short of endogenizing trade policy. ${ }^{5}$ Findlay and Kierzkowski (1983) present an OLG model in continuous time where agents decide on human capital acquisition. Borsook (1987) introduces heterogenous agents in such a framework and Falvey, Greenaway, and Silva (2007) allow for skill acquisition later in life to analyze the role of age in trade adjustment. Though not a trade paper per se, Eicher (1996) touches on a similar set of issues in his elegant study of the interaction between skill acquisition decisions and endogenous technological innovation in a full OLG framework. Matsuyama (1992) uses a similar setup where agents, whose comparative advantage differs across sectors, decide up-front which sector to enter depending on current and future trade policies. Notably, his closing sentence advocates future work to analyze the "dynamic formation of commercial policy" - precisely the aim of the present paper.

Finally, instead of using a full OLG model, numerous trade studies consider a finite sequence of time periods where heterogenous agents can make decisions. Davidson, Matusz, and Nelson (2007) show that the relative timing of decisions on trade liberalization and compensation can lead to different policy outcomes. Bougheas and Riezman (2007) analyze how the distribution of human capital determines the respective trade policies of two countries. Willmann (2004) shows how the attempt to compensate the losers from liberalization can undermine the gains from trade due to strategic under-investment in human capital, while Long, Riezman, and Soubeyran (2007) analyze how trade liberalization affects the acquisition of sector specific human capital.

The paper proceeds as follows. Section 2 describes the model and establishes the conditions under which multiple political steady states exist. Section 3 then describes the

\footnotetext{
${ }^{5}$ Dynamic models have also been used to study the labor market aspects of trade policy, though this literature is methodologically distant from the model developed here. For example, Davidson and Matusz (2004) present an OLG model that features a search process to enter the higher value sector, and Davidson, Martin, and Matusz (1999) employ a continuous time model with infinitely lived agents, while Davidson and Matusz (2006) focus on the transition between steady states. In a similar spirit, Cameron, Chaudhuri, and McLaren (2002), Artuc, Chaudhuri, and McLaren (2003), and Artuc (2006) use dynamic stochastic models of labor movement to study intersectoral adjustment costs facing workers subsequent to trade policy changes.
} 
potential for transition between steady states, focussing first on the role of expectations and then on active policy prescriptions for inducing reform. Section 4 concludes.

\section{$2 \quad$ A Model of Political Stasis}

The model is designed to capture a dynamic environment in which both current and future trade policy influence individuals' skill acquisition decisions and voting behavior. Our OLG approach highlights the importance of current policy in determining both the existing skill composition of workers - and thus the identity (not just the policy preference) of the median voter - and the intra- and inter-generational political friction borne of different abilities to adjust between unskilled and skilled work. The model allows formal evaluation of the endogeneity of voters' preferences and choices with current and expected economic conditions, representing how voters populations may evolve in response to changing economic conditions.

Equilibrium in this model has two components: economic and political. We begin in Section 2.1 by defining an economic equilibrium as the skill composition and production levels that would result from an exogenous time path of tariffs; an economic steady state is then just the economic equilibrium that would obtain under a constant exogenous tariff level. Section 2.2 then endogenizes the political process to evaluate the existence, properties, and potential multiplicity of Markov perfect political equilibria and political steady states. As in Krishna and Mitra (2006) we first develop the model without inclusion of tariff revenue to simplify the analytical exposition. Appendix B demonstrates the robustness of the results to lump sum redistribution of tariff revenue. ${ }^{6}$

\subsection{The Model Economy}

The model consists of a small open economy that may produce, consume, and trade two goods: a skill-based good, $S$, which requires skilled labor to produce, and a basic good,

\footnotetext{
${ }^{6}$ Redistribution through non-uniform tariff revenue rebates is analytically equivalent to the tax and transfer scheme discussed in Section 3.
} 
$U$, produced using unskilled labor. Let good $S$ be the economy's natural export good. Designating $U$ as numeraire, the domestic relative price of good $S$ then is given by $p \equiv \frac{p^{w}}{\tau}$, where $p^{w}$ represents the exogenous world relative price and $\tau$ is defined as one plus the advalorem tariff on the basic good. Both goods are produced under perfect competition with constant returns to scale technologies. There is no uncertainty in the model and borrowing and lending are ruled out. ${ }^{7}$

The economy's population consists of a continuum of agents with ex-ante heterogeneous natural abilities and rational expectations with perfect foresight. ${ }^{8}$ Agents live for two periods; thus at any point in time, two generations, the 'young' and the 'old', comprise the total population. Every generation is assumed to be the same size, with mass normalized to one. Individuals of each generation are indexed by $a \in[0,1]$ according to ability level. We assume that within each generation, the distribution of ability levels is uniform over the unit interval. Agent $a=0$ is the least able of her generation, and agent $a=1$ the most able.

Every agent is endowed with one unit of labor in each period of life. At birth, each individual chooses either to remain unskilled for her lifetime or to acquire skills at a constant fixed education cost $c \in[0,1]$ units of labor. If an agent elects to remain unskilled, she inelastically supplies one unit of unskilled labor in each period of her life. If instead she chooses to earn an education, she supplies the $(1-c)$ units of unskilled labor that remain after paying for education when young, and subsequently $(1+a)$ efficiency units of skilled labor when old. Comparing the sectoral mobility of both age groups, note that agents are assumed to be free to choose between sectors when young, while they are sectorally immobile when old. ${ }^{9}$

We assume an extreme form of factor specificity in the production functions for both

\footnotetext{
${ }^{7}$ Given the structure of the model, agents are unable to make binding future commitments to each other, across or within generations. In assuming the voters cannot commit to future political positions or voting behaviors we follow Hassler et al (2003), among others.

${ }^{8}$ Introducing individual uncertainty over future policy outcomes into the model would only strengthen our results further, by compounding the status quo bias as in Fernandez and Rodrik (1991).

${ }^{9}$ Falvey, Greenaway, and Silva (2007) who allow agents to earn an education at any point along a continuous time dimension show that sectoral mobility does decrease in age.
} 
goods: the basic good is produced only from unskilled labor and the skill-based good solely from skilled labor. ${ }^{10}$ While our assumption that each good uses only one factor of production simplifies analysis, this is not a necessary condition for our results. ${ }^{11}$

An agent will acquire skills only if doing so will maximize her lifetime indirect utility. Preferences are identical across individuals and functionally separable across time. Let each agent's lifetime utility function be given by:

$$
u\left(x_{u}^{y}, x_{s}^{y}\right)+\beta u\left(x_{u}^{o}, x_{s}^{o}\right)
$$

where $\beta>0$ represents the intertemporal discount factor, $x_{s}^{y}\left(x_{u}^{y}\right)$ denotes the individual's consumption of good $S(U)$ when she is young, and $x_{s}^{o}\left(x_{u}^{o}\right)$ her consumption of good $S$ $(U)$ when old. We assume intratemporal utility is a function of current consumption, given by $u\left(x_{u}, x_{s}\right) \equiv x_{s}^{\alpha} x_{u}^{1-\alpha}$, so that the corresponding within-period indirect utility function is $v(p, I) \equiv K p^{-\alpha} I$, where $K \equiv \alpha^{\alpha}(1-\alpha)^{1-\alpha}>0, I$ denotes current nominal income, and $\alpha \in(0,1)$.

By choice of units, one unit of unskilled labor produces exactly one unit of the basic good, so that the nominal wage to unskilled labor is normalized to one for all agents. From the assumption that one unit of skilled labor by agent $a$ produces $(1+a)$ units of good $S$, perfect competition implies that the nominal skilled wage to agent $a$ at time $t$ is $(1+a) p_{t}$. Thus, as a function of current and future prices, $p_{t}$ and $p_{t+1}$, a given agent $a$ will acquire skills only if:

$$
v\left(p_{t}, 1-c\right)+\beta v\left(p_{t+1},(1+a) p_{t+1}\right) \geq v\left(p_{t}, 1\right)+\beta v\left(p_{t+1}, 1\right) .
$$

From 2.2 and the functional form of the sub-utility function in 2.1 we can define the threshold agent, $\hat{a}_{t}$, under a diversified equilibrium as the member of the young generation

\footnotetext{
${ }^{10}$ Unskilled workers cannot produce skill-based goods, and no established skilled (second generation) worker would revert to unskilled good production as long as the skill premium is positive, which is implied in autarky by the Cobb-Douglas structure of preferences assumed momentarily, and under trade by the assumption that $S$ is the natural export good.

${ }^{11}$ As in Matsuyama (1992) our assumption simplifies the analysis by reducing the dimensionality of the price vector and relieves us of resorting to the Stolper-Samuelson result, which would deliver the same results under a more general production structure.
} 
at time $t$ who is just indifferent between remaining unskilled and getting an education given the discount rate, the cost of education, the preference parameter $\alpha$, and current and anticipated tariffs:

$$
\hat{a}_{t}\left(\tau_{t}, \tau_{t+1}\right) \equiv \max \left\{0, \frac{\beta+c\left(\frac{\tau_{t}}{\tau_{t+1}}\right)^{\alpha}}{\beta p^{w}} \tau_{t+1}-1\right\} .
$$

Note that the corner solution in which all agents acquire skills, $\hat{a}=0$, does not imply a specialized economy (as long as $c<1$ ), since all workers are assumed to be unskilled while young. The assumption that the country has comparative advantage in production of the skill-based good ensures that $\hat{a}<1$ in equilibrium.

Based on the critical value in (2.3), we can summarize the educational decisions of any agent as follows:

Proposition 2.1 An agent of generation $t$ with ability level $a \in[0,1]$ remains unskilled for life if $a \leq \hat{a}\left(\tau_{t}, \tau_{t+1}\right)$, and acquires skills otherwise.

Because each generation of agents is mapped to the unit interval with a uniform distribution, $\hat{a}$ also equals the proportion of unskilled workers in each generation. For notational convenience, we define an economic equilibrium in terms of the equilibrium proportion of each generation that acquires skills: $\theta_{t} \equiv 1-\hat{a}_{t}$. Output of each good at time $t$ then may be written as a function of the skill composition of the old (generation $t-1$ ) and the young (generation $t$ ). Since the parameters $\left(p^{w}, \beta, c, \alpha\right)$ are assumed to be fixed and exogenous, we suppress these arguments in definitions hereafter.

Definition 2.1 Economic Equilibrium. As a function of an exogenous tariff sequence, an economic equilibrium is characterized by the currently young and older generations' skill composition and current levels of production over time in each sector so that $\forall t$ :

$$
\begin{aligned}
\theta_{t}\left(\tau_{t}, \tau_{t+1}\right) & =2-\frac{\beta+c\left(\frac{\tau_{t}}{\tau_{t+1}}\right)^{\alpha}}{\beta p^{w}} \tau_{t+1} \\
\theta_{t-1}\left(\tau_{t-1}, \tau_{t}\right) & =2-\frac{\beta+c\left(\frac{\tau_{t-1}}{\tau_{t}}\right)^{\alpha}}{\beta p^{w}} \tau_{t} \\
q_{t}^{u}\left(\theta_{t-1}, \theta_{t}\right) & =2-\theta_{t-1}-c \theta_{t}, \\
q_{t}^{s}\left(\theta_{t-1}\right) & =\int_{\hat{a}_{t-1}}^{1}(1+a) d a=2 \theta_{t-1}-\frac{\theta_{t-1}^{2}}{2} .
\end{aligned}
$$


Since the model assumes a small open economy, ${ }^{12}$ the definition of an economic steady state is trivial. For a given world price, $p^{w}$, economic equilibrium is determined uniquely by the last period, current, and next-period tariffs; thus, if the tariff is fixed (and this is understood by voters), an economic steady state is reached. Formally:

Definition 2.2 Economic Steady State. The steady state economic equilibrium under a constant tariff level $\tau$ is characterized by a constant skill composition across generations and a constant level of production in each sector according to:

$$
\begin{aligned}
\theta(\tau) & =2-\frac{\beta+c}{\beta p^{w}} \tau, \\
q_{u}(\theta) & =2-(1+c) \theta, \\
q_{s}(\theta) & =2 \theta-\frac{\theta^{2}}{2} .
\end{aligned}
$$

\subsection{The Political Process}

We model the political process as a direct democracy over trade policy. ${ }^{13}$ At the beginning of each period, every agent in the population votes on current trade policy, which subsequently determines the wages and prices for that period. Agents have complete information and perfect foresight when they make their voting decisions. We adopt a binary referendum framework; ${ }^{14}$ agents can vote either to maintain the status quo tariff policy, $\tau^{o}$, or to switch to some alternate regime, $\tau^{\prime}$. The two possible tariff regimes, denoted $\tau_{L}$ and $\tau_{P}$, are for

\footnotetext{
${ }^{12}$ The derivation of the autarkic steady state and autarkic steady state price is offered in the appendix.

${ }^{13}$ Other forms of political competition would of course change the analysis considerably, but we argue that the qualitative underpinning of our findings - that there exists a feedback mechanism between economic policy outcomes and endogenous policy decisions that can lead to multiple equilibria and political stasis will obtain for a broad class of political economy models.

${ }^{14}$ The assumption of a binary policy framework is less restrictive than it first appears. As demonstrated later in this section, agents in our model have extreme policy preferences- every worker (with the exception of one (zero mass) "indifferent voter") strictly prefers complete protection (autarky) or the free trade (and indeed, import subsidies if possible). Thus, if the median voter was permitted to choose her most preferred tariff (in essence, deciding the structure of the referendum), she would choose one trade policy extreme or the other rather than some intermediate tariff. Since interior tariffs would never be chosen by a median voter, the binary referendum structure we adopt imposes little loss of generality. This issue is discussed further in Section 3.5
} 
now taken as given, assumed to be fixed by a third party agenda setter whose objectives are the focus of Section 3. Without loss of generality, let $\tau_{L}<\tau_{P}$ and think of the former as the liberal and the latter as the protectionist tariff. We define the reform step as $\Delta \equiv \tau^{o}-\tau^{\prime}$, so that $\Delta>0$ represents a trade liberalization from $\tau_{P}$ to $\tau_{L}$, while $\Delta<0$ would imply a protectionist shift from $\tau_{L}$ to $\tau_{P}$. We assume that there is no bureaucratic or time cost of changing tariff regimes.

Trade policy is determined by majority vote. In the case of a tie, we assume that the status quo is maintained. If half or more of the population (i.e. voting mass $\geq 1$; recall that the mass of the total population is 2) votes in favor of the status quo tariff policy the tariff regime remains unchanged and the existing tariff regime is deemed politically stable. If instead the majority votes for reform, the tariff switches to the proposed alternative regime immediately. As in any majoritarian voting model, the median voter - hereafter with characteristics denoted by superscript ${ }^{M}-$ is decisive.

We define a political equilibrium to be any economic equilibrium in which agents' expected time path of tariffs would be maintained endogenously under the existing political process. As in Hassler, Rodríguez Mora, Storesletten, and Zilibotti (2003), we restrict attention to Markov perfect equilibria, requiring that voters' behavior depends only on payoff relevant state variables. ${ }^{15}$ In the context of this model, the state variables include the fixed parameters $p^{w}, \beta, c$, and $\alpha$, and the existing skill composition of the older generation, which will determine the identity of the median voter (demonstrated below). Recalling that the skill composition of the older generation at time $t$ is denoted $\theta_{t-1}$, we then have the following:

Definition 2.3 Political Equilibrium. A Markov perfect political equilibrium is defined by a policy rule, $\tau_{t}=T\left(\theta_{t-1}\right)$, where $T:[0,1] \rightarrow\left\{\tau_{P}, \tau_{L}\right\}$ is a time-invariant mapping from the current skill composition of the older generation to the current voting outcome and $\theta_{t-1}=\theta\left(\tau_{t-1}\right)$, where $\theta:\left\{\tau_{P}, \tau_{L}\right\} \rightarrow[0,1]$ is a time invariant mapping from the status quo (last period) tariff to the current skill composition of the older generation such that $\forall t$ :

\footnotetext{
${ }^{15}$ By requiring Markov perfect voting strategies, we effectively rule out the potential for stochastic beliefs that can generate sun-spot equilibria. We discuss the potential role of changing beliefs in Section 3.1.
} 
1. $T\left(\theta_{t-1}\right)=\arg \max _{\tau_{t} \in\left\{\tau_{P}, \tau_{L}\right\}} v_{t}^{M}\left(\tau_{t}, \tau_{t+1} ; a^{M}, p^{w}, \beta, c, \alpha\right)$ s.t. $\tau_{t+1}=T\left(\theta\left(\tau_{t}\right)\right)$ and

2. $\theta_{t}=\theta\left(\tau_{t}\right)=2-\frac{\beta+c\left(\frac{\tau_{t}}{\tau_{t+1}}\right)^{\alpha}}{\beta p^{w}} \tau_{t+1}$, s.t. $\tau_{t+1}=T\left(\theta\left(\tau_{t}\right)\right)$.

The first condition requires that the median voter at time $t$ chooses the current tariff $\tau_{t} \in\left\{\tau_{P}, \tau_{L}\right\}$ to maximize her lifetime indirect utility, $v_{t}^{M}(\cdot)$, with the rational expectation that the next period's tariff will depend on the implied skill composition of the currently young cohort according to the same policy mapping. The second condition requires that the skill composition of each cohort is determined in (economic) equilibrium as in (2.4), again subject to the rational expectation that $\tau_{t+1}=T\left(\theta\left(\tau_{t}\right)\right)$.

We define a political steady state to be any economic steady state in which the status quo policy (hereafter denoted by $\tau^{o} \equiv \tau_{t-1}$ ) would be maintained endogenously under the existing political process. Thus, a political steady state defined under the referendum structure given by the tariff pair $\left(\tau_{L}, \tau_{P}\right)$ is an economic steady state given by $(2.8)$ - $(2.10)$ under either initial tariff regime, $\tau^{o} \in\left\{\tau_{L}, \tau_{P}\right\}$, in which the median voter would elect to maintain the status quo tariff policy over the competitive equilibrium that would arise under the proposed alternative. Formally:

Definition 2.4 Political Steady State. A political steady state is reached when $\tau_{t} \equiv$ $T\left(\theta\left(\tau_{t-1}\right)\right)=\tau_{t-1}$. A political steady state is summarized by the (constant) skill composition of the population under the steady state tariff, $\bar{\tau}$ :

$$
\theta(\bar{\tau})=2-\frac{\beta+c}{\beta p^{w}} \bar{\tau}
$$

Our framework provides a straightforward environment for evaluating political equilibria. We begin by arranging both generations of voters over the uniform population interval $[0,2]$ in weakly ascending order of each individual's preference for trade openness; the most protectionist voters are indexed closest to zero, the most liberal are indexed closest to 2 . We can then exploit the structure of the model to characterize the identities of two key voters among the population at any given time: the median voter, whose vote is decisive in the referendum, and the indifferent voter, who separates the population between those who 
prefer the more protectionist regime and those who would prefer the more liberal tariff policy. We consider the trade policy preferences of each generation in turn, allowing us to map individuals to the population interval by weakly increasing preference for trade openness.

Older Voters. It is immediate that members of the older generation will be polarized in the trade policy debate. Because older workers are intersectorally immobile, the older unskilled (import-competing) workers have an unambiguous preference for the highest possible tariff (autarky), while all of the older skilled workers prefer the smallest tariff possible. (For semantic convenience we will refer to this as free trade, keeping in mind that it could be a trade subsidy in the absence of a non-negativity constraint on the tariff.) Restating, we have that:

Proposition 2.2 Among the older generation, political support for the liberal tariff regime is non-decreasing in ability level: the unskilled (lower ability) older agents strictly prefer the protectionist regime, while the skilled (higher ability) older agents strictly prefer the more liberal tariff policy.

To confirm that the most preferred trade policy by any older worker is necessarily a corner solution, simply note that the indirect utility of older unskilled (skilled) workers is strictly decreasing (increasing) in the local relative price according to:

$$
\begin{aligned}
V^{u, o} & =v(p, 1)=K p^{-\alpha} 1 \\
V^{s, o} & =v(p,(1+a) p)=K p^{1-\alpha}(1+a) .
\end{aligned}
$$

Starting from an economic equilibrium at time $t$ in which the skill composition of older workers is given by $\theta_{t-1}$, fraction $\left(1-\theta_{t-1}\right)$ of the older generation is unskilled and thus unambiguously favors autarky; these voters can then be lined up on the left-most end of the $[0,2]$ population interval. Likewise, proportion $\theta_{t-1}$ of the older generation is unambiguously pro free trade and therefore can be stacked at the top end of the population interval. Accordingly, the younger generation spans the population interval from $\left[1-\theta_{t-1}, 2-\theta_{t-1}\right]$. It is immediate that the median voter must be a member of the young generation; by 
definition, the median voter is the individual at the center of the population interval (namely agent $j=1$ ) and since $\theta_{t-1} \leq 1$ by definition, the young generation necessarily spans the median of the overall population.

Young Voters. Assessing the trade policy preferences of the pivotal younger generation is somewhat more involved than for the older cohort because, unlike their older counterparts, the young can adjust their educational decisions in response to the current realization of tariff policy. It is still the case that every agent's most preferred tariff will be characterized by a corner solution so that the young generation, like the old, can be divided into those who unambiguously prefer protectionism and those wholeheartedly in favor of free trade. But from there the story is complicated by the endogeneity of the skill acquisition decision. Intuitively, the young agents of each natural ability level can be characterized as either lifetime net producers or net consumers of the basic good, depending on the current and anticipated tariff levels. Members of the former group will favor protectionism (the lower the relative price of the skill-based good, the better) while the lifetime net suppliers of skillbased goods may or may not prefer free trade, depending on the cost of education relative to higher expected wages from freer trade in the second period of life.

A simple observation provides substantial leverage in evaluating both the structure of trade policy preferences among the young generation and the characteristics of political equilibria. Notice that for any fixed future tariff, every young voter would strictly prefer protectionism in the current period. ${ }^{16}$ (Recall that all workers are assumed to provide unskilled labor in the first period of life regardless of whether or not they undergo training to become skilled workers in the future.) Thus, even a pro-reform young voter would strictly prefer "protection today and free trade tomorrow" to "free trade today and free trade tomorrow." This implies that the only reason that a young voter would vote for liberalization in the current period is to influence the voting outcome in the next period.

This universal preference for high tariffs while young (again, holding future tariff

\footnotetext{
${ }^{16}$ Under the extreme parametric assumption that $c=1$ such that agents cannot earn wages as unskilled workers when undergoing skill-acquisition process, young future-skilled workers would be indifferent over first-period trade policy (holding second period trade policy fixed).
} 
policy fixed) allows us to rule out the possibility of a protectionist shift from $\tau_{L}$ to $\tau_{P}$ in political equilibrium, which implies in turn that we can rule out the possibility of temporary deviations from either status quo policy. ${ }^{17}$ If the median voter expects protection in the future, she would never vote for the liberal regime in the current period; we therefore can rule out the possibility of temporary liberalization in political equilibrium. A similar argument rules out the possibility of temporary protection: if starting from a liberal regime, a young voter at time $t$ expected that she could deviate temporarily to protection (returning to a liberal regime in the next period), then by rational expectations her predecessor at $t-1$ would have anticipated this behavior and thus voted for protection as well, contradicting the initial assumption a liberal status quo at time $t$.

Since temporary deviations from the status quo cannot occur in equilibrium, we can reduce young voters' policy preferences to a choice between permanent maintenance of the status quo versus a permanent and immediate shift to the proposed alternate regime. To characterize how trade policy preferences depend on young voters' skill acquisition decisions, we categorize the young generation into three groups: those who would upgrade their skills under either policy regime (the high ability agents), those who would educate themselves only under the more liberal policy regime (the middle ability agents), and those who would remain unskilled under either regime (the low ability agents). Using $\hat{a}_{P} \equiv \hat{a}\left(\tau_{P}, \tau_{P}\right)$ $\left(\hat{a}_{L} \equiv \hat{a}\left(\tau_{L}, \tau_{L}\right)\right)$ to denote the ability of the threshold agent under a current and future protectionist (liberal) regime according to (2.3), and recalling that $\hat{a}$ is increasing in $\tau$ (the greater the level of import protection, the higher the ability of the threshold agent and the lower the skill composition of the population) so that $\hat{a}_{P} \geq \hat{a}_{L},{ }^{18}$ the three types of agents are sorted on the generational unit interval as summarized in the following proposition. Figure 1 illustrates.

\footnotetext{
${ }^{17}$ That is, we can rule out the possibility of political equilibria that include tariff sequences $\tau_{t-1} \rightarrow \tau_{t}=$ $\tau_{L} \rightarrow \tau_{P}$. The temporary deviation time paths: $\tau_{t-1} \rightarrow \tau_{t} \rightarrow \tau_{t+1}=\tau_{L} \rightarrow \tau_{P} \rightarrow \tau_{L}$ or $\tau_{P} \rightarrow \tau_{L} \rightarrow \tau_{P}$, are thereby ruled out.

${ }^{18}$ The inequality is weak only in the corner scenario in which all agents would choose to acquire skills under both tariff regimes; i.e. $\hat{a}_{P}=\hat{a}_{L}=0$.
} 
Proposition 2.3 For any pair of tariff alternatives, $\left\{\tau_{L}, \tau_{P}\right\}$, there are three types of young agents:

i) low ability agents with ability $a \leq \hat{a}_{L}$, who would remain unskilled under either constant (current and future) tariff regime, $\tau_{L}$ or $\tau_{P}$;

ii) middle ability agents with ability $a \in\left(\hat{a}_{L}, \hat{a}_{P}\right]$, who would acquire skills under the liberal regime but not under the protectionist regime; and

iii) high ability agents with $a>\hat{a}_{P}$, who would acquire skills under either (current and future) tariff regime, $\tau_{L}$ or $\tau_{P}$.

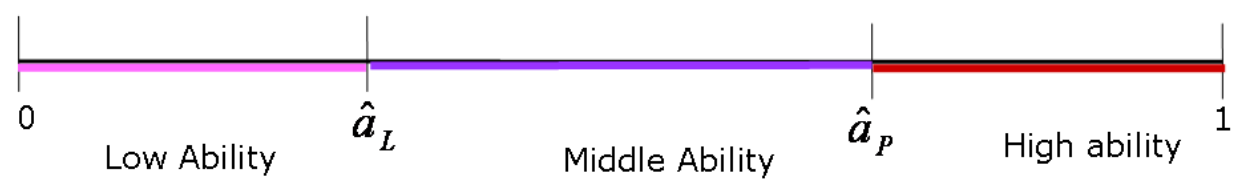

Figure 1: Young Generation Ability Types

The lowest ability members of the young generation are the easiest to evaluate, so we start there. Since these least able workers will remain unskilled under either tariff policy, 
the low ability agents unambiguously favor protectionism. Thus, we can stack fraction $\hat{a}_{L}$ of the young generation alongside their older counterparts on the left hand side of the population interval.

The middle ability agents, those with ability levels $a \in\left(\hat{a}_{L}, \hat{a}_{P}\right]$, will educate only under the expectation of the more liberal tariff regime. The proportion of the middle ability group that supports the more liberal tariff regime (if any) depends on the tradeoff between first period unskilled wages and education cost and second period income. This friction between current and future real earnings does not imply, however, that individually optimal tariffs are interior; quite the opposite, the members of the middle ability group prefer either autarky or free trade depending on prices and parameters (including education cost and the discount factor) and their individual specific ability level. A middle ability agent will vote in favor of the more liberal regime if:

$$
\begin{aligned}
v\left(p_{P}, 1\right)+\beta v\left(p_{P}, 1\right) & \leq v\left(p_{L}, 1-c\right)+\beta v\left(p_{L},(1+a) p_{L}\right) \\
\Longleftrightarrow a & \geq \frac{\tau_{P}^{\alpha} \tau_{L}^{-\alpha}(1+\beta)-(1-c)}{\beta p^{w}} \tau_{L}-1 .
\end{aligned}
$$

This expression demonstrates that the higher ability agents within the group would be the first to support freer trade; the higher an agent's ability, the higher her skilled wage and hence the greater her expected gains from liberalization.

Like the rest of the population, each high ability agent's most preferred trade policy is characterized by a corner solution. A high ability agent $a \in\left(\hat{a}_{P}, 1\right]$ will support the more liberal regime $\left(\tau_{L}\right)$ if:

$$
\begin{aligned}
v\left(p_{P}, 1-c\right)+\beta v\left(p_{P},(1+a) p_{P}\right) & \leq v\left(p_{L}, 1-c\right)+\beta v\left(p_{L},(1+a) p_{L}\right) \\
\Longleftrightarrow a & \geq \frac{\left(\tau_{P}^{\alpha}-\tau_{L}^{\alpha}\right)}{\left(\tau_{L}^{\alpha-1}-\tau_{P}^{\alpha-1}\right)} \frac{1-c}{\beta p^{w}}-1 .
\end{aligned}
$$

Thus, we again find that the highest ability agents among the group will be the first in line to support liberalization. The expressions in (2.14) and (2.15) coincide at the border between the high and middle ability groups (where $a=\hat{a}_{P}$ ) so that if (2.14) or (2.15) holds with equality for some $a^{\prime} \in\left(\hat{a}_{L}, 1\right]$, then $(2.14)((2.15))$ holds with strict equality for all agents $a \in\left(a^{\prime}, a^{P}\right]\left(a>a^{\prime} \cap\left(\hat{a}_{P}, 1\right]\right)$ and is violated for all $a<a^{\prime}$. Interestingly, even the 
highest ability agents of the young generation will not necessarily favor free trade. This ambiguity in trade policy preferences is again driven by friction between unskilled earnings in the first stage of life and skilled earnings in the second period of life.

We summarize our findings as follows:

Proposition 2.4 Among the young generation, the political support for the liberal tariff regime is non-decreasing in ability level;

i) Low ability agents with $a \in\left[0, \hat{a}_{L}\right)$ strictly prefer the protectionist regime;

ii) of the middle ability agents with $a \in\left[\hat{a}_{L}, \hat{a}_{P}\right)$, those with individual ability less (greater) than $\tilde{a}_{m} \equiv \frac{\tau_{P}^{\alpha} \tau_{L}^{-\alpha}(1+\beta)-(1-c)}{\beta p^{w}} \tau_{L}-1$ prefer the high (low) tariff,

iii) of the high ability agents with $a \in\left[\hat{a}_{P}, 1\right]$, those with individual ability less (greater) than $\tilde{a}_{h} \equiv \frac{\left(\tau_{P}^{\alpha}-\tau_{L}^{\alpha}\right)}{\left(\tau_{L}^{\alpha-1}-\tau_{P}^{\alpha-1}\right)} \frac{1-c}{\beta p^{w}}-1$ prefer the high (low) tariff.

This proposition implies that the young voters can be indexed over the population interval in increasing ability type. For any initial skill composition of the older generation, $\theta_{t-1}$, then, the young generation can be arranged ascending in ability type over the interval $\left[1-\theta_{t-1}, 2-\theta_{t-1}\right]$ of the population support $[0,2]$. Based on this ordering we can identify and compare first, the indifferent agent who separates the protectionists from the free-traders and second, the median voter.

The Indifferent Voter. We define the indifferent voter to be the (zero mass) individual who separates the population between the protectionists and the free traders. It is clear that the indifferent voter is neither a member of the young low ability type nor of the older generation, since all of these individuals strictly prefer autarky or free trade. The indifferent voter therefore must be a member of the young generation in either the middle or high ability groups. Using $\tilde{a}$ to label the ability level of this delineating individual, we note that if the indifferent voter is a middle ability type so that $\tilde{a} \in\left(\hat{a}_{L}, \hat{a}_{P}\right]$, then she is the agent for whom:

$$
\tilde{a}_{m}=\frac{\tau_{P}^{\alpha} \tau_{L}^{-\alpha}(1+\beta)-(1-c)}{\beta p^{w}} \tau_{L}-1
$$


Alternatively, if the indifferent agent is a member of the high ability group, her identity is given by:

$$
\tilde{a}_{h}=\frac{\left(\tau_{P}^{\alpha}-\tau_{L}^{\alpha}\right)}{\left(\tau_{L}^{\alpha-1}-\tau_{P}^{\alpha-1}\right)} \frac{1-c}{\beta p^{w}}-1
$$

For any quadruple of parameter values, $\left(\beta, c, \alpha, p^{w}\right)$ and pair of tariff alternatives, $\left(\tau_{L}, \tau_{P}\right)$, then, the system of equations (2.16)-(2.17) pins down the indifferent voter:

Proposition 2.5 The indifferent agent is a young voter of middle or high ability. If $\tilde{a}_{m} \in$ $\left[\hat{a}_{L}, \hat{a}_{P}\right)$, she is a middle ability agent and if $\tilde{a}_{h} \in\left[\hat{a}_{P}, 1\right]$, she is high ability.

Notice that because the indifferent voter is young, her identity is independent of the status quo tariff policy or the skill composition of the older generation.

The Median Voter. Since fraction $1-\theta_{1-t} \leq 1$ of the older generation is protectionist and the young voters are mapped to the population interval according to ability type, the identity of the median voter is immediate:

Proposition 2.6 The median voter at time $t$ is the member of the young generation with ability level $a_{t}^{M} \equiv a^{M}\left(\tau_{t-1}, \tau_{t}\right)=\theta_{t-1}$. Furthermore, the median voter is of lower ability under protectionism than under the liberal regime: $a^{M}\left(\tau_{P}, \tau_{P}\right)<a^{M}\left(\tau_{L}, \tau_{L}\right)$.

The identity of the median voter therefore depends on both the status quo and realized contemporary tariff regimes through the skill composition of the older generation. As one might expect, the ability level of the median voter is decreasing with the measure of older unskilled workers $\left(1-\theta_{t-1}\right)$; the greater the vested interest in a high tariff among the older generation, the more difficult it will be to implement tariff liberalization, since only a small proportion of the young vote is needed to block a proposed reform. Conversely, the greater the skill composition of the older workers, the higher the ability of the median voter and the better the chance for the liberal regime. Figure 2 summarizes. 


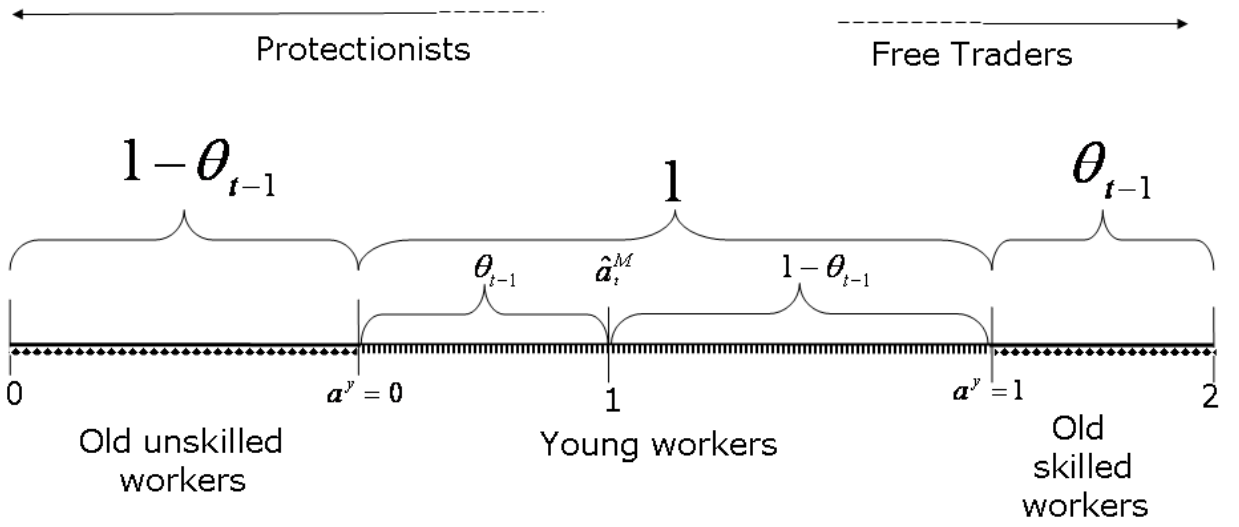

Figure 2: The Population Interval by Trade Policy Preference

\subsection{Political Equilibria}

We evaluate the existence of political equilibria by comparing the relative position of the median and indifferent voters on the population interval. If the indifferent voter lies to the left of the median voter, then the median voter will favor free trade and thus vote for the liberal regime; if instead the indifferent voter lies to the right of the median voter, the protectionist regime will succeed in the referendum. The key is to recognize that under rational expectations and individually optimal skill acquisition decisions, the identity of the median voter depends on both the status quo and realized tariff regimes according to Proposition 2.6. In contrast, the identity of the indifferent voter is independent of the status quo tariff, pinned down on the population interval for any pair of tariff alternatives by $\tilde{a}\left(\tau_{L}, \tau_{P}\right)$.

For any pair of possible tariff regimes, $\tau_{L}$ and $\tau_{P}$, the equilibrium skill composition of the older generation can take three possible values: $\theta\left(\tau_{P}, \tau_{P}\right), \theta\left(\tau_{L}, \tau_{L}\right)$, or $\theta\left(\tau_{P}, \tau_{L}\right)$, 
depending on the status quo and current tariff policy. ${ }^{19}$ Following Proposition 2.6, there are then three possible median voters identified on the population interval: the young agents with ability $a^{M}\left(\tau_{P}, \tau_{P}\right), a^{M}\left(\tau_{P}, \tau_{L}\right)$, and $a^{M}\left(\tau_{L}, \tau_{L}\right)$. From (2.4), we verify that $a^{M}\left(\tau_{P}, \tau_{P}\right)<a^{M}\left(\tau_{P}, \tau_{L}\right)<a^{M}\left(\tau_{L}, \tau_{L}\right)$; intuitively, the ability level of the median voter will be lowest when the older generation makes its skill acquisition decisions under the expectation of lifetime protectionist trade policy, and highest when older workers anticipate a lifetime of freer trade. For any set of parameter values and tariff alternatives, the position of the indifferent voter among these potential median voters determines the set of political equilibrium possibilities. There are three important cases to consider, which we characterize as follows:

Proposition 2.7 Depending on the relative position of the indifferent and median voters over the young generation interval, there are three possibilities:

i) $a^{M}\left(\tau_{L}, \tau_{L}\right)<\tilde{a}$ : the steady state with $\tau_{t}=\tau_{P} \forall t$ is the unique politically stable equilibrium.

ii) $\tilde{a}<a^{M}\left(\tau_{P}, \tau_{P}\right)$ : the steady state with $\tau_{t}=\tau_{L} \forall t$ is the unique politically stable equilibrium.

iii) $a^{M}\left(\tau_{P}, \tau_{P}\right) \leq \tilde{a} \leq a^{M}\left(\tau_{L}, \tau_{L}\right)$ : both steady states, $\tau_{t}=\tau_{P} \forall t$ and $\tau_{t}=\tau_{L} \forall t$, are politically stable equilibria.

The first two are simple but relatively uninteresting scenarios in which the unique political equilibrium is characterized by a political steady state under either $\tau_{L}$ or $\tau_{P}$. First, if the indifferent voter lies to the right of all three potential median voter ability levels so that every potential median would voter favor the protectionist regime, the unique political equilibrium is characterized by the political steady state under $\tau_{P}$ according to (2.11). The second possibility is the opposite extreme in which the median voter lies to the left of all

\footnotetext{
${ }^{19}$ Recall that $\theta\left(\tau_{L}, \tau_{P}\right)$ can be eliminated immediately from the discussion of political equilibria, pursuant to the discussion on page 15, which rules out the possibility of a protectionist shift from $\tau_{L}$ to $\tau_{P}$ in any political equilibrium.
} 
three potential median voters such that the political steady state under $\tau_{L}$ is the unique political equilibrium. These possibilities are depicted in Panels A and B in Figure 3.

Panel A:

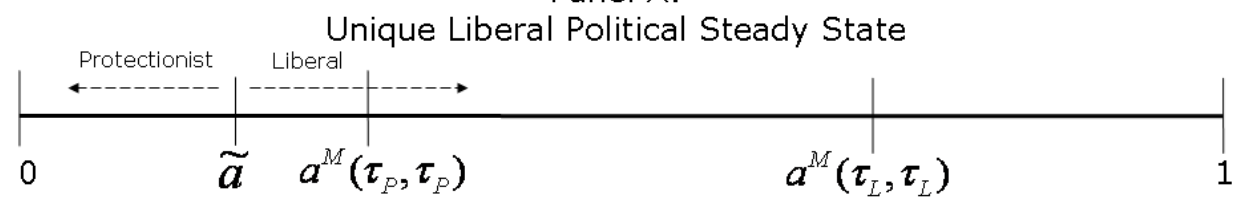

Panel B:

Unique Protectionist Political Steady State

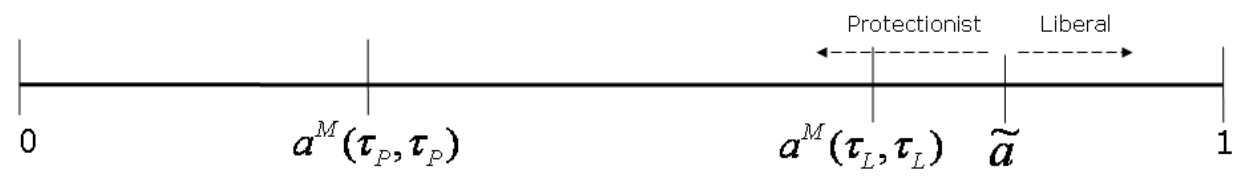

Panel C:

Multiple Political Steady States



Figure 3: Political Steady States

The focus of this paper is of course the intermediate possibility in which the indifferent voter lies between the median voter that would obtain under either steady state tariff policy (i.e. $\tilde{a}\left(\tau_{L}, \tau_{P}\right) \in\left[a^{M}\left(\tau_{P}, \tau_{P}\right), a^{M}\left(\tau_{L}, \tau_{L}\right)\right]$ as in Panel $\mathrm{C}$ of Figure 3$)$ so that there exist multiple political steady states; starting from a protectionist status quo the median voter would vote to maintain protection, while starting from the liberal status quo policy, the median voter would vote to maintain the lower tariff.

The case of multiple political steady states consists of two possible scenarios- in the first, $a^{M}\left(\tau_{P}, \tau_{P}\right)<a^{M}\left(\tau_{P}, \tau_{L}\right)<\tilde{a}\left(\tau_{L}, \tau_{P}\right)<a^{M}\left(\tau_{L}, \tau_{L}\right)$; in this instance, the two political steady states are the only forms of political equilibria. ${ }^{20}$ The remaining case in

\footnotetext{
${ }^{20}$ The median voter that would obtain if the older generation had voted for protection when young but expected liberalization in the second stage of life, $a^{M}\left(\tau_{P}, \tau_{L}\right)$, would favor protection- thus generating a contradiction.
} 
which $a^{M}\left(\tau_{P}, \tau_{P}\right)<\tilde{a}\left(\tau_{L}, \tau_{P}\right)<a^{M}\left(\tau_{P}, \tau_{L}\right)<a^{M}\left(\tau_{L}, \tau_{L}\right)$, permits a third, belief-driven, possibility in which the time path of trade policy is characterized by a single transition from the protectionist regime to freer trade; starting from a protectionist status quo, voters can rationally expect reform to occur in the next period because the induced median voter in the next period, $a^{M}\left(\tau_{P}, \tau_{L}\right)$, would indeed favor the liberal regime. It should be emphasized, however, that this potential for "organic" reform is not consistent with Markov perfect political equilibrium without some exogenous (and payoff-relevant) spark to induce a shift in beliefs the period before liberalization occurs. ${ }^{21}$ To see this, consider a candidate political equilibrium time path of tariffs characterized by a one time transition from the protectionist regime to the liberal tariff at time $t^{*}$. In a Markov perfect equilibrium, the $t^{*}-1$ generation's beliefs about next period tariffs must be identical to the beliefs of generation $t^{*}-2$ since the payoff-relevant state variables are identical at the time of each generation's birth (before $\left.t^{*}\right)$. Thus, the only Markov perfect equilibrium possibilities are political steady states, as specified in Proposition 2.7.

\subsection{Existence of Multiple Political Steady States}

The conditions under which multiple political steady states can obtain naturally depends on parameter values and the choice of tariff alternatives $\tau_{L}$ and $\tau_{P}$. A simple graphical exposition proves worthwhile for thinking about the set of possibilities.

Notice first that the fraction of skilled workers under a protectionist steady state, $\theta\left(\tau_{P}, \tau_{P}\right)$, must be less than the fraction of skilled workers under the relatively liberal steady state, $\theta\left(\tau_{L}, \tau_{L}\right)$, because $\tau_{L}<\tau_{P}$ by assumption and $\theta$ is strictly decreasing in the (steady state) tariff according to (2.8); thus, it must be true that $a^{M}\left(\tau_{P}, \tau_{P}\right)=\theta\left(\tau_{P}, \tau_{P}\right)<$ $a^{M}\left(\tau_{L}, \tau_{L}\right)=\theta\left(\tau_{L}, \tau_{L}\right)$, ruling out the shaded region in Figure 4. Second, note that if less than half of the population is skilled under even the more liberal tariff regime, so that $a^{M}\left(\tau_{P}, \tau_{P}\right)<a^{M}\left(\tau_{L}, \tau_{L}\right)<\frac{1}{2}$, then the median voter under either initial tariff regime must be a member of the low ability group so that $\tau_{P}$ can be the only political steady state in region IV of Figure 4. Conversely, if more than half of the population would be skilled

\footnotetext{
${ }^{21}$ The potential government role in spurring belief-induced reform is discussed further in Section 3.1.
} 
under even the more protectionist regime, so that $\frac{1}{2}<a^{M}\left(\tau_{P}, \tau_{P}\right)<a^{M}\left(\tau_{L}, \tau_{L}\right)$ as in region I of Figure 4, the indifferent voter under either initial tariff regime must necessarily be a member of the high ability group. This does not, imply, however, that there are necessarily multiple political steady states or even that the more liberal regime is a steady state, since even high ability voters may be protectionists (for example, if $\beta$ is very small). Finally, if $a^{M}\left(\tau_{P}, \tau_{P}\right)<\frac{1}{2}<a^{M}\left(\tau_{L}, \tau_{L}\right)$ there are two possibilities, both of which may (but need not) give rise to multiple equilibria. First if $a^{M}\left(\tau_{P}, \tau_{P}\right)<1-a^{M}\left(\tau_{L}, \tau_{L}\right)$ as in region III, the median voter starting from $\tau_{P}\left(\tau_{L}\right)$ will be a member of the low skill (medium skill) group so that $\tau_{P}$ will definitely be one steady state, but $\tau_{L}$ may or may not be politically stable as well. Alternatively, if $a^{M}\left(\tau_{P}, \tau_{P}\right)>1-\hat{a}^{M}\left(\tau_{L}, \tau_{L}\right)$ as in region II, the median voter starting from $\tau_{P}\left(\tau_{L}\right)$ will be a member of the middle skill (high skill) group so that $\tau_{L}, \tau_{P}$, or both may be politically stable. ${ }^{22}$

The question that arises, then, is if the economy is in a "bad" equilibrium from national welfare maximization standpoint - a protectionist rut characterized by the political steady state under $\tau_{P}$ - whether and how it can transition to the more liberal steady state under $\tau_{L}$. The answer is the focus of the next section, which explores the possibility of different mechanisms for transitioning between steady states.

\section{Transition Mechanisms}

In asking how a protectionist political steady state can be escaped, we effectively assume the existence of a third party agenda setter whose objective is national welfare maximization - i.e. trade liberalization. It is understood that the cause of transition out of steady state must lie outside of the political process modelled so far, as the median voter under the protectionist regime - once she is in place - has no interest in such a change. We argue that our conceptual framework with a third party agenda setter is a reasonable approximation to the political structure observed in many democracies, particularly in the determination

\footnotetext{
${ }^{22}$ We have confirmed that each of the regions depicted in Figure 4 is non-empty for some reasonable set of parameters.
} 


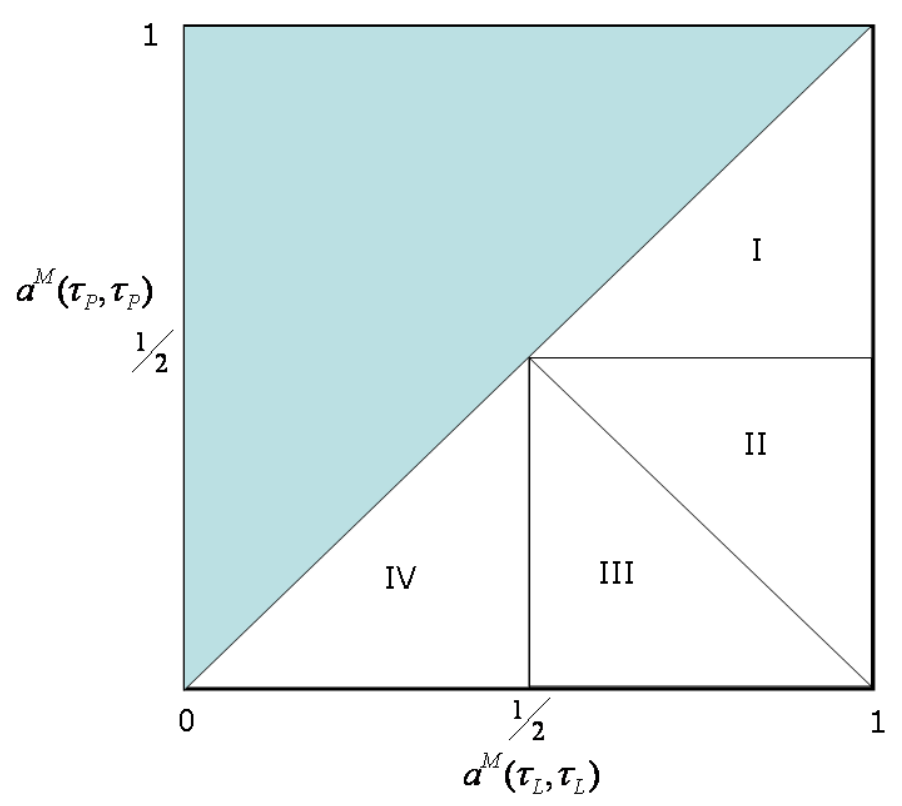

Figure 4: Potential Multiple Equilibria

of trade policy. It is often the case that a few political elites - frequently un-elected - define the structure of political platforms or the design of ballot referenda to be put forward to the voting public. Indeed, this agenda setting extends beyond the populist vote to the halls of representative democracy. In the United States, for instance, fast track negotiating authority grants the President (who ostensibly represents the welfare objectives of the country as a whole) the right to design the structure of proposed trade agreements, each of which is subsequently sent to Congress (composed of heterogeneous district and state representatives) only for the final up or down referendum.

\subsection{Announcements and Organic Political Change}

Political stability hinges on agents' expectations over future trade policy. In particular, if the economy is caught in the protectionist steady state, the high tariff regime is perpetuated by agents' self-fulfilling beliefs that the same regime will still be in place next period. And it 
is this very belief that leads to skill acquisition decisions and a subsequent skill composition which in turn bring about a median voter next period who decides to keep in place this regime. One possibility to break away from this vicious circle is to alter agents' expectations over future trade policy. If young workers anticipate freer trade in the future, they will upgrade their skills accordingly. This anticipatory skill upgrading will in turn increase the skill composition of the older generation in the next period and thus the future constituency in favor of liberalization.

Notice that if the potential future constituency supporting free trade is sufficiently large, an "organic" political shift from a protectionist steady state to a liberal steady state is possible in political equilibrium, contingent on an exogenously induced shift in agents' beliefs. To see this, suppose that $\tilde{a}\left(\tau_{L}, \tau_{P}\right) \in\left[a^{M}\left(\tau_{P}, \tau_{P}\right), a^{M}\left(\tau_{L}, \tau_{L}\right)\right]$ so that both steady states are political equilibria. Then, if starting from a protectionist steady state at time $t-1$, enough members of the then-young generation would upgrade their skills under the expectation of more liberal trade at time $t$ so that $\theta_{t-1}=\theta\left(\tau_{P}, \tau_{L}\right)=a^{M}\left(\tau_{P}, \tau_{L}\right)>\tilde{a}\left(\tau_{L}, \tau_{P}\right)$, the expectation of freer trade at time $t$ is rational so that such an equilibrium transition from the protectionist regime to the liberal steady state marks a third form of political equilibrium in addition two the two steady states, as stated in the following proposition:

Proposition 3.1 If $a^{M}\left(\tau_{P}, \tau_{P}\right) \leq \tilde{a}\left(\tau_{L}, \tau_{P}\right) \leq a^{M}\left(\tau_{P}, \tau_{L}\right)$ and $\tau_{t}=\tau_{P}$ for all $t \leq T$, then an exogenous change in beliefs of the young in period $T$ from expecting protection to expecting the liberal regime in period $T+1$ leads to a transition from the protectionist steady state to the liberal steady state from period $T+1$ onward.

At the same time, however, the assumption of Markov perfection implies that agents' beliefs must be intertemporally stable; that is, agents cannot simply wake up one day with new beliefs about the future. And so the question becomes how expectations can be altered to bring about reform. Forces that can bring about a change in anticipated future policy could be new actors from either outside or inside the country itself. Inside actors could be elder statesmen or political pundits weighing in on trade policy or politicians' announcements of anticipated future trade deals. Outside actors could be foreign governments pushing for 
multilateral trade talks or applying political pressure for reform cast as "inevitable". Even the popular press could bring about changes in beliefs - and thus reform - without changing the parameters underlying the model simply by suggesting that change is on the horizon. ${ }^{23}$

In practice, the credibility of announcements will play an important role in shaping expectations about the future, even if organic political reform is possible. We would expect that an outside actor seeking to induce a shift in expectations would most likely need to rely on a commitment device, such as a bilateral treaty or impending accession to, for example, the World Trade Organization or the European Union, unless she possesses a form of inherent credibility. ${ }^{24}$

\subsection{External Terms of Trade Changes}

The political support for trade reform depends in large part on the skill composition of the population, which in turn is determined - apart from trade policy - by the terms of trade, so far taken as given. A favorable shift in the country's terms of trade, by increasing the relative price of the export good, makes skill acquisition more profitable and therefore leads to a higher proportion of the population acquiring skills. By lowering the critical ability level, it changes the identity of the median voter: her ability level is higher the more favorable the terms of trade, as there are fewer unskilled individuals among the old who oppose liberalization. At the same time, a change in the terms of trade has no first order effect on the identity of the indifferent agent among the young. Thus:

Proposition 3.2 An exogenous improvement in the terms of trade increases the political support for trade liberalization.

\footnotetext{
${ }^{23}$ Markov perfection requires that beliefs are based on payoff-relevant state variables, so such a change in beliefs must be predicated on some "real" change in the state of the world. A vanishingly small lump sum $\operatorname{tax} \epsilon \rightarrow 0$ would serve such purpose of changing state variables to free the belief structure without meaningful secondary effects.

${ }^{24}$ While a junior representative from Wisconsin may be unlikely to convince voters of any impending change, even a few casual words from a former Federal Reserve Chairman could convey the necessary gravitas to immediately shift voters' beliefs.
} 
Among the many forces that could shift a country's terms of trade, we are especially interested in trade policy decisions taken by trading partners. Suppose a large trading partner liberalizes trade, for example by lowering the import tariff on the skill-intensive good that the country under consideration exports to its partner. This unilateral liberalization on part of the partner country will result in a favorable shift in the home country's terms of trade. As outlined above the change in the terms of trade shifts the window of median voters to the right. And as the median voters are of higher ability and more pro-trade, the liberalized regime tends to become politically stable (if it was not), the transition equilibrium becomes feasible, and the protectionist regime loses political stability.

This positive correlation between unilateral trade policy decisions by large trading partners opens up the possibility of multiple equilibria in a non-cooperative international trade policy game. The reason is that trade liberalization on part of the other country makes domestic liberalization politically feasible, and vice versa. ${ }^{25}$ Such a multiplicity of equilibria in the international context comes in addition to the inherent multiplicity of equilibria that our model exhibits in a purely unilateral context. Indeed, the latter is among the key novelties of our model, as we demonstrate the potential for multiple equilibria even for small countries without any change in the terms of trade. ${ }^{26}$

\subsection{Trade Adjustment Assistance: Temporary Education Subsidies}

Another mechanism, apart from changing beliefs, to affect the skill composition and thereby the decision on trade policy lies in altering directly the economic calculations that determine the skill acquisition decision. The obvious way to influence this decision in the desired way is to subsidize the acquisition of skills. This can be achieved by enacting a subsidy to education that reduces the cost of acquiring skill and is financed by a poll tax. By tilting the balance in favor of skill acquisition, such a subsidy will improve the skill composition of the cohort and - if sufficiently substantial — bring about a median voter who favors trade liberalization. Note that once we have moved towards the new free-trade steady state,

\footnotetext{
${ }^{25}$ This mechanism has been pioneered by Krishna and Mitra (2005) and Krishna and Mitra (2006).

${ }^{26}$ We are grateful to Devashish Mitra for emphasizing this point.
} 
the subsidy could be abolished if,as in the case of multiple political steady states, the new liberal steady state is politically stable even without the subsidy.

Formally, let $s \in[0, c]$ denote the (gross) subsidy paid to every young agent who decides to acquire skills, which reduces the cost of doing so from $c$ to $c-s$. This subsidy must be funded and a balanced budget on part of the government implies that the poll tax required to do so amounts to $t=\frac{s}{2} \hat{\theta}_{t}$. Taking this into account, equation (2.2) that governs the skill acquisition decision has to be modified as follows:

$$
v\left(p_{t}, 1-(c-s)-t\right)+\beta v\left(p_{t+1},(1+a) p_{t+1}-t\right) \geq v\left(p_{t}, 1-t\right)+\beta v\left(p_{t+1}, 1-t\right),
$$

where it has been assumed that the agent expects the policy to be in place for the two periods of her lifetime. ${ }^{27}$ This results in the following modified critical ability level:

$$
\hat{a}_{t}\left(\tau_{t}, \tau_{t+1}\right) \equiv \frac{\beta+(c-s)\left(\frac{\tau_{t}}{\tau_{t+1}}\right)^{\alpha}}{\beta p^{w}} \tau_{t+1}-1 .
$$

Clearly, the education subsidy decreases the critical ability level and thus increases the proportion of the cohort that decides to acquire skills. Note that the poll tax itself does not directly influence the education decision as it has to be paid whether one acquires skills or not.

Similar to the analysis in the baseline case, the skill acquisition decision determines the identity of the median voter among the young, via the skill composition of the old generation. In particular, the identity of the median voter in steady state is given by:

$$
a_{t}^{M}\left(\tau_{t-1}, \tau_{t}\right) \equiv \hat{\theta}_{t-1}\left(\tau_{t-1}, \tau_{t}\right)=2-\frac{\beta+(c-s)\left(\frac{\tau_{t-1}}{\tau_{t}}\right)^{\alpha}}{\beta p^{w}} \tau_{t}
$$

As before the ability level of the median voter is decreasing in the steady state tariff level because a higher tariff leads to more support for protection among the old. At the same time, the education subsidy reduces the support for protection by increasing the number of skilled older workers. Correspondingly, the median voter's ability level is increasing in the education subsidy.

\footnotetext{
${ }^{27}$ Note that this assumption can be relaxed. Assuming the subsidy to be in place for one period would only alter the value of the tax , which has no effect on the skill acquisition decision.
} 
We now draw attention to how the education subsidy affects the identity of the indifferent voter. As before, we have to distinguish two cases: the case where the indifferent voter acquires skills under both regimes and the case where she decides to acquire skills only when the tariff is low. ${ }^{28}$ In the first case, the identity of the indifferent voter takes the form:

$$
\tilde{a}_{m}=\frac{\tau_{L}^{\alpha}\left(1-c+s-(1+\beta) t_{0}\right)-\tau_{P}^{\alpha}\left(1-c+s-(1+\beta) t_{1}\right)}{\beta\left(\tau_{P}^{\alpha} p_{1}-\tau_{L}^{\alpha} p_{0}\right)}-1 .
$$

In the second, it is:

$$
\tilde{a}_{h}=\frac{\tau_{L}^{\alpha}(1+\beta)\left(1-t_{0}\right)-\tau_{P}^{\alpha}\left(1-c+s-(1+\beta) t_{1}\right)}{\beta p_{1}}-1 .
$$

How does the education subsidy affect these identities? Differentiating with respect to the subsidy $s$ and taking into account the government's budget constraint, it is straightforward to show that $\tilde{a}_{2}^{\prime}(s)<\tilde{a}_{1}^{\prime}(s)<0$. We thus have:

Proposition 3.3 A poll-tax funded education subsidy $s>0$ has the political effects

$$
\partial \tilde{a}_{m} / \partial s<\partial \tilde{a}_{h} / \partial s<0<\partial a^{M} / \partial s
$$

and thus increases (decreases) the political viability of the liberal (protectionist) steady state regime.

We see that whereas the ability levels and hence the identities of the respective median voter under each steady state increase with the education subsidy, the reverse happens to the indifferent voter. This increase in the ability level is more pronounced in the second case, as the indifferent voter acquires skills no matter what in the first case so that we have only second order effects. This opens up the possibility that the ability level of the indifferent voter falls below the identity of the median voter in the protectionist steady state. When this happens, the protectionist regime becomes politically unstable implying the education subsidy will cause a transition from the protectionist to the more liberal regime with the ensuing welfare benefits overall. Figure 5 illustrates:

\footnotetext{
${ }^{28}$ Note that the case where the indifferent voter never acquires skills (i.e. is of low ability) still cannot arise; indeed, the education subsidy tends to increase every agent's incentive to acquire skills.
} 


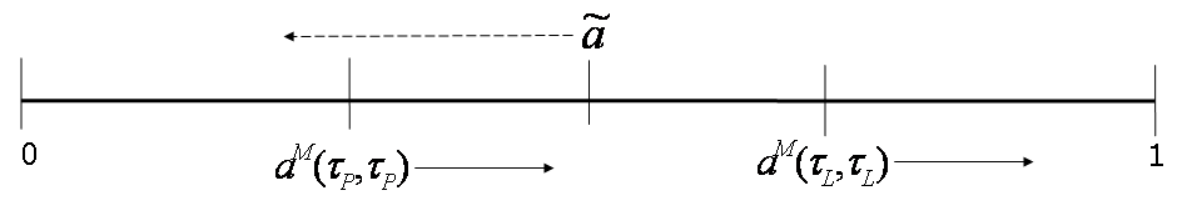

Figure 5: The Effect of Education Subsidies

It is important to note the less desirable side-effect of education subsidy on the (net of transfers) wage gap between skilled and unskilled workers: because all workers are taxed to pay for the education subsidy, the lowest ability workers who will remain unskilled even in the presence of a subsidy are taxed at the expense of their higher ability contemporaries. The tariff liberalizing benefit of blanket educational subsidies thus should be weighed against the concomitant increase in income inequality between low and high ability agents. But as pointed out above, once transition has occurred the education subsidy can as well be abolished provided that the indifferent voter has a lower ability level than the median in the liberalized steady state without the education subsidy. The implied increase in income inequality therefore would be temporary also.

Taking a moment to relate the just derived results to the analysis in the earlier subsection on announcements and beliefs, note that the identity of the median voter in a transitional period, $a^{M}\left(\tau_{P}, \tau_{L}\right)$ also moves to the right according to the general equation 
(3.3) above. Even if the indifferent agent does not lie to the left of the median voter under protectionism, she could find herself to the left of the transitional median voter, $a^{M}\left(\tau_{P}, \tau_{L}\right)$. This indicates that a combination of education subsidies and announcements can be successful even if the education subsidy is not sufficient to render the protectionist steady state politically unstable on its own. And again, the subsidy can be abolished in this scenario once transition has been achieved.

\subsection{Trade Adjustment Assistance: Transfers}

Among the most commonly found policy supplements to trade reform in developed countries are compensation schemes that partially offset the losses faced by workers who are adversely affected from trade liberalization. Unlike the transition mechanisms discussed thus far, which appear to be suitable means to achieve freer trade, transfer programs designed to compensate the losers from trade liberalization turn out to be counter-productive. This result is particularly striking given that unemployment compensation or wage "top ups" are a prominent component of most countries' existing trade adjustment assistance (TAA) programs.

In order to compensate workers in import competing sectors, TAA transfer programs must tax the winners from trade reform. In our context, this implies that transfers depress the skill premium since the economy is assumed to hold comparative advantage in the skillbased good. Similar to the educational subsidies analyzed above, this changes the economic profitability of skill acquisition, but now in the opposite direction. Skill acquisition becomes less attractive under such a policy and this makes trade liberalization even harder to achieve politically, even though the trade adjustment component makes it appear more palatable at first sight.

Formally, suppose the unskilled old receive a subsidy $s$ per person as soon as trade liberalization is enacted..$^{29}$ To balance the budget the government needs to raise taxes and it does so by introducing a poll tax of $t$ to be paid by the skilled. ${ }^{30}$ Modifying the model

\footnotetext{
${ }^{29}$ The unskilled young cannot expect such a payment as they still have the option to acquire skills.

${ }^{30}$ Note that the skilled with relatively low ability actually lose from trade liberalization. However, trade
} 
accordingly, we can derive the new critical ability level for skill acquisition:

$$
\hat{a}_{t}\left(\tau_{t}, \tau_{t+1}\right) \equiv \frac{\beta(1+s+t)+c\left(\frac{\tau_{t}}{\tau_{t+1}}\right)^{\alpha}}{\beta p^{w}} \tau_{t+1}-1 .
$$

Clearly, the subsidy $s$ and the tax $t$ have to satisfy the government budget constraint, $\hat{a}_{t-1}\left(\tau_{t-1}, \tau_{t}\right) s=\left(1-\hat{a}_{t-1}\left(\tau_{t-1}, \tau_{t}\right)\right) t$, where we note that the cut-off ability level reflects the skill composition of the older generation. Substituting the budget constraint and totally differentiating, we obtain the following effects on the transitional critical ability level:

$$
\frac{\partial \hat{a}\left(\tau_{P}, \tau_{L}\right)}{\partial t}=\frac{1}{\hat{a}\left(\tau_{P}, \tau_{P}\right) p_{t+1}}>0
$$

and similarly, the steady state critical ability level under the liberalized regime:

$$
\frac{\partial \hat{a}\left(\tau_{L}, \tau_{L}\right)}{\partial t}=\frac{1+t /\left(\hat{a}\left(\tau_{L}, \tau_{L}\right)^{2} p_{t+1}\right)}{\hat{a}\left(\tau_{L}, \tau_{L}\right) p_{t+1}}>0
$$

whereas the critical ability level under steady state protectionism remains unchanged as no compensation ever takes place. Accordingly, the median voter under the liberal steady state is now of a lower ability type, as - less pronounced - is her transitional counterpart, whereas the median voter under the protectionist steady state is of the same type as without transfers. In other words, the respective median voters tend to move left, contrary to our results for the education subsidy.

We turn now to the indifferent agent. If she is a member of the medium ability group, she is characterized by

$$
\tilde{a}_{m}=\frac{\tau_{P}^{\alpha} \tau_{L}^{-\alpha}(1+\beta)-(1-c)}{\beta p^{w}} \tau_{L}-1+\frac{t}{p^{w}} \tau_{L}
$$

Alternatively, if she belongs to the high ability group, she is of ability level

$$
\tilde{a}_{h}=\frac{\left(\tau_{P}^{\alpha}-\tau_{L}^{\alpha}\right)}{\left(\tau_{L}^{\alpha-1}-\tau_{P}^{\alpha-1}\right)} \frac{1-c}{\beta p^{w}}-1+\frac{t \tau_{L}^{\alpha}}{\tau_{L}^{\alpha-1}-\tau_{P}^{\alpha-1}}
$$

It is clear that both possible indifferent agents move to the right, i.e. are now of a higher ability type.

adjustment programs typically do not make this distinction, basing compensation on employment status rather than overall worker welfare. 
Given that the median voters under the transitional equilibrium and especially under the liberal steady state move left, and the indifferent agents move right, we conclude that the political feasibility of trade liberalization diminishes:

Proposition 3.4 Trade adjustment assistance to the unskilled workers in the older generation, financed by a poll-tax $t$, has the political effects

$$
\partial a^{M}\left(\tau_{L}, \tau_{L}\right) / \partial t<\partial a^{M}\left(\tau_{P}, \tau_{L}\right) / \partial t<0<\partial \tilde{a}_{m} / \partial t<\partial \tilde{a}_{h} / \partial t
$$

and thus decreases (increases) the political viability of the liberal (protectionist) steady state regime.

Transfer augmented trade liberalization might not be politically stable at all, even if without transfers liberalization would have been, or it might not be reachable by a shift in beliefs only. That is, we have the perverse effect that transfers, though seemingly appealing, actually render trade liberalization more difficult or even impossible to achieve.

\subsection{Radical Reform}

This section explores a different thought experiment, asking whether there are preconditions on the structure of a liberalization referendum necessary for reform to be possible - or conversely, if starting from a liberal policy regime, there exist some forms of protectionist proposals that necessarily would induce the economy to revert to protectionism. As discussed earlier, we are effectively asking how a third party agenda setter (not the median voter) could influence the extant and future political steady state by altering the structure of referendum proposals.

¿From the analysis in Section 2.2 it is clear that the existence of any political steady state depends not only on the status quo tariff, but also on the alternative regime, since the identity of the indifferent voter (and hence implicitly the trade preferences of the median voter) depend on the pair of tariff alternatives; i.e. $\tilde{a} \equiv \tilde{a}\left(\tau_{L}, \tau_{P}\right)$. The policy question is then: starting from a given regime, which proposed tariff alternatives (if any) would ensure that the status quo is maintained as the unique political steady state, which would lead 
to an unambiguous regime shift by making the status quo politically unstable, and which referendum alternatives would admit the already much discussed possibility of multiple equilibria? We assume that the referendum must be structured as a choice between the status quo and some alternative regime, ${ }^{31}$ and we refer to a proposed tariff alternative as "reform" if it decreases the tariff and as "entrenchment" otherwise.

Perhaps surprisingly, we find that the best way to block reform (apart from offering entrenching tariff proposals) is to propose a relatively minor tariff liberalization. Starting from a protectionist steady state, a tariff liberalization referendum is sure to fail for a sufficiently small reform step, since (tautologically) $\lim _{\tau^{\prime} \rightarrow \tau_{P}} a^{M}\left(\tau_{P}, \tau^{\prime}\right)=a^{M}\left(\tau_{P}, \tau_{P}\right)$. That is, the median voter who would obtain if voters rationally expected a shift from the protectionist regime to the alternative regime is vanishingly close to the status quo protectionist median voter, as the reform step converges to zero.

Proposition 3.5 There exists a sufficiently small critical reform step size $\Delta$ such that the status quo tariff $\tau_{P}$ is politically stable against any alternative tariff $\tau^{\prime}<\tau_{P}$ if $\tau_{P}-\tau^{\prime}<\Delta$.

One way to see the point is in Figure 4. Suppose for example that $a^{M}\left(\tau_{P}, \tau_{P}\right) \leq \frac{1}{2}$, and that, for some initial tariff alternative, $\tau^{\prime}<\tau_{P}, \theta\left(\tau^{\prime}, \tau^{\prime}\right)=a^{M}\left(\tau^{\prime}, \tau^{\prime},\right) \geq \frac{1}{2}$ so that the initial tariff proposal may admit multiple political steady states under Region II or III. Decreasing the reform step by decreasing $\Delta$ then causes $a^{M}\left(\tau^{\prime}, \tau^{\prime}\right)$ to move left, toward $a^{M}\left(\tau_{P}, \tau_{P}\right)$, eventually pushing the economy into Region IV where the only political steady state is the protectionist regime.

Figure 6 offers an alternative demonstration using a numerical example to evaluate the range of tariff liberalization proposals that admit multiple steady states. ${ }^{32}$ Given an initial benchmark protectionist regime, $\tau_{P}$, and set of parameter values $\left(\alpha, \beta, c, p^{w}\right)$, we

\footnotetext{
${ }^{31}$ Alternative assumptions both would be inconsistent with the nature of referenda (almost always a choice about whether or not to adopt a policy change), but also would yield uninteresting results. (The agenda setter could ensure a political shift simply by making the two prosed regimes different from the status quo (and vanishingly similar), and could maintain the status quo simply by offering the degenerate "choice" between the status quo and itself.)

${ }^{32}$ We thank Devashish Mitra for suggesting this form of graphical representation.
} 
can derive the identities of both the median and the indifferent voters among the young generation as a function of the proposed tariff alternative, $\tau .{ }^{33}$ Focussing on the case of tariff reform, we assume that $\tau \leq \tau_{P} \cdot{ }^{34}$ For values of the tariff alternative at which $\tilde{a}\left(\tau_{P}, \tau\right)>$ $a^{M}(\tau, \tau)$ (the median voter under the proposed liberal regime would favor protectionism), the unique political steady state will be the protectionist regime. Alternatively, proposed tariff alternatives under which $\tilde{a}\left(\tau_{P}, \tau\right)<a^{M}(\tau, \tau)$, support two political steady states both the proposed alternative and the protectionist status quo.

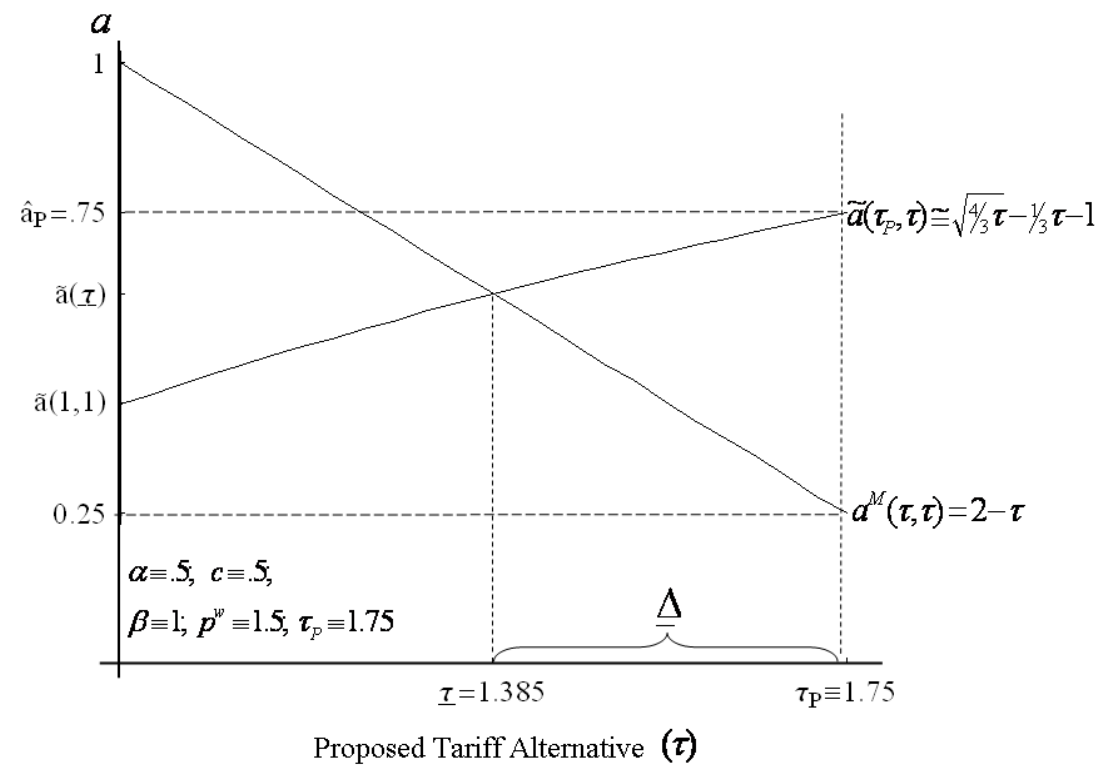

Figure 6: Minimum Reform Step

It is immediate that there exists a range of tariff reform proposals, $\tau \in\left(\underline{\tau}, \tau_{P}\right)$ that are too modest to admit even the possibility of reform, since they are not themselves politically stable. Conversely, more radical tariff reform proposals - those with a reform step greater

\footnotetext{
${ }^{33}$ For the purposes of demonstration and ease of calculation, we set $\alpha \equiv .5, c \equiv .5, \beta \equiv 1, p^{w} \equiv 1.5$, and $\tau_{P}=1.75$.

${ }^{34}$ We note that the alternative case of tariff entrenchment is simply the inverse of the scenario discussed herein.
} 
than $\underline{\Delta}$ - are politically stable and therefore permit the potential for reform through the policy channels identified in earlier subsections. Intuitively, since voters' preferences are unambiguously protectionist or pro free trade, no voter would strictly prefer a small reform to radical reform; there are no moderate voters (except the zero-mass indifferent voter), only two extremist voter blocks. Reducing the magnitude of the reform step therefore serves only to decrease the potential consistency of skilled workers who would favor liberalization.

Our finding that radical reform may be necessary to generate the political support for tariff reform parallels the similar finding by Krishna and Mitra (2006) whose intuition applies equally in this context: because voters' political allegiances depend on their (net lifetime) sectoral orientation, and are monotonically increasing in the relative price of the good in which they have comparative advantage, a big shift in the proportion of the population employed in the export oriented (skill-based) sector is necessary to generate political support for reform. But while in their model, shifting workers' sectoral orientation requires exogenous changes in terms of trade, this section demonstrates that (potential) political support for tariff reform can be generated by sufficiently radical liberalization proposals.

\section{Conclusion}

This paper evaluates the dynamic political economy aspects of tariff reform in the presence of populist politics. The model is designed in such a way to capture $(i)$ a dynamic environment, specifically the potential influence of current policy on the identity (not just the policy preferences) of the median voter, (ii) the political frictions both within and across generations borne of different abilities to adjust to changing economic conditions, and (iii) the endogeneity of voters' preferences and choices with current and expected economic conditions. Populations can and do evolve in response to economic conditions, even in the presence of myopic preferences; this paper constructs a simple model to evaluate how and why these changes can (and sometimes do not) occur.

We find that multiple political steady states may exist within an economy, and thus, that voters can potentially get stuck in a protectionist rut despite that aggregate welfare 
would be higher under a more liberal tariff regime. A series of thought experiments and comparative statics exercises demonstrate that the multiplicity of political equilibria can be broken through a number of third party induced changes. We discuss several potential mechanisms for escaping the protectionist rut: announcements of future policy commitments (for instance, preferential trade agreement talks) that change young voters' beliefs about the future; terms of trade improvements triggered by trading partners' unilateral tariff reforms; temporary education subsidies that reduce the cost of skill acquisition and thus increase the political constituency in favor of open markets; and structuring referenda to put forward substantial reform packages rather than minor policy changes. We also find, perhaps provocatively, that transfer payments to negatively impacted workers in the importcompeting sectors will reduce the potential for reform unless they are carefully constructed in such a way that they do not influence young workers' skill acquisition decisions.

There are a number of promising extensions to be pursued in subsequent research. From a theoretical perspective, it would be interesting to move away from the restricted set of Markov perfect equilibria to explore further the role of beliefs and sun-spot equilibria. Empirically, cross country panel studies could explore the potential influence of variations in educational access, cost, and education, differential voter turnout across generations, and welfare programs on the success of trade reform and public ratification of regional integration agreements. Finally, one could envision formal policy analysis of the optimal structure of the trade adjustment assistance (TAA) programs focussed on generational differences that would offer transfer payments to "buy out" old unskilled workers, while offering only education subsidies to younger, less able, workers.

\section{References}

Artuc, E. (2006, October). Intergenerational effects of trade liberalization: Structural estimation of a dynamic model of labor mobility.

Artuc, E., S. Chaudhuri, and J. McLaren (2003). Delay and dynamics in labor market adjustment: Simulation results. Columbia Department of Economics Discussion 
Series 0304-0\%.

Bassetto, M. (1999). Political economy of taxation in an overlapping-generations model. Federal Reserve Bank of Minneapolis Discussion Paper no. 133.

Basu, K. and P. H. Van (1998). The economics of child labor. American Economic Review $88(3), 412-427$.

Benabou, R. (2000). Unequal societies: Income distribution and the social contract. American Economic Review 90, 96-129.

Borsook, I. (1987). Earnings, ability and international trade. Journal of International Economics 22, 281-95.

Bougheas, S. and R. Riezman (2007). Trade and the distribution of human capital. Journal of International Economics (forthcoming).

Cameron, S., S. Chaudhuri, and J. McLaren (2002). Mobility costs and the dynamics of labor market adjustment to external shocks: Theory. Columbia Department of Economics Discussion Series 0102-53.

Davidson, C., L. Martin, and S. Matusz (1999). Trade and search generated unemployment. Journal of International Economics 48(2), 271-299.

Davidson, C. and S. Matusz (2004). An overlapping-generations model of escape clause protection. Review of International Economics 12(5), 749-768.

Davidson, C. and S. Matusz (2006). Long-run lunacy, short-run sanity: a simple model of trade with labor market turnover. Review of International Economics 14(2), 261-276.

Davidson, C., S. Matusz, and D. Nelson (2007). Can compensation save free trade. Journal of International Economics 71(1), 167-86.

Eicher, T. S. (1996). Interaction between endogenous human capital and technological change. Review of Economic Studies 63(1), 127-144.

Falvey, R., D. Greenaway, and J. Silva (2007, February). Trade liberalization and human capital adjustment. Mimeo. 
Fernandez, R. and D. Rodrik (1991). Resistance to reform: Status quo bias in the presence of individual specific uncertainty. American Economic Review 81, 1146-1152.

Findlay, R. and H. Kierzkowski (1983). International trade and human capital: A simple general equilibrium model. Journal of Political Economy 91(6), 957-978.

Glomm, G. and B. Ravikumar (1995). Endogenous public policy and multiple equilibria. European Journal of Political Economy 11, 653-62.

Hassler, J., J. V. Rodríguez Mora, K. Storesletten, and F. Zilibotti (2003). The survival of the welfare state. American Economic Review 93, 87-112.

Krishna, P. and D. Mitra (2005). Reciprocated unilateralism in trade policy. Journal of International Economics 65.

Krishna, P. and D. Mitra (2006). Reciprocated unilateralism in trade reforms with majority voting. Journal of Development Economics forthcoming.

Krusell, P., V. Quadrini, and J. Ríos-Rull (1996). Are consumption taxes really better than income taxes? Journal of Monetary Economics 37, 475-503.

Krusell, P. and J. Ríos-Rull (1996). Vested interestes in a positive theory of stagnation and growth. Review of Economic Studies 62, 301-29.

Long, N. V., R. Riezman, and A. Soubeyran (2007). Trade, wage gaps, and specific human capital accumulation. Review of International Economics.

Magee, C., C. Davidson, and S. Matusz (2005). Trade, turnover, and tithing. Journal of International Economics 66, 157-176.

Maggi, G. and A. Rodríguez-Clare (2006). A political-economy theory of trade agreements. Mimeo.

Maggi, G. and A. Rodríquez-Clare (1998). The value of trade agreements in the presence of political pressures. Journal of Political Economy 106, 574-601.

Matsuyama, K. (1992). A simple model of sectoral adjustment. Review of Economic Studies 59, 375-87. 
McLaren, J. (2002). A theory of insidious regionalism. Quarterly Journal of Economics $117,571-608$.

Ohnsorge, F. and D. Trefler (2004). Sorting it out: International trade and protection with heterogeneous workers. NBER Working Paper 10959.

Ortega, F. (2004). Immigration and the survival of the welfare state. Mimeo.

Saint Paul, G. (2001). The dynamics of exclusion and fiscal conservatism. Review of Economic Dynamics 4, 155-68.

Saint Paul, G. and T. Verdier (1997). Power, distributive conflicts, and multiple growth paths. Journal of Economic Growth 2, 155-68.

Staiger, R. and G. Tabellini (1987). Discretionary trade policy and excessive protection. American Economic Review 77, 823-37.

Willmann, G. (2004). Pareto gains from trade: A dynamic counter-example. Economics Letters 83, 199-204.

Yeaple, S. R. (2005). A simple model of firm heterogeneity, international trade, and wages. The Journal of International Economics 65, 1-20.

\section{A1 Autarkic Equilibrium}

The autarkic equilibrium price, $p^{a}$, and skill composition of the older generation, $\theta\left(p^{a}\right)$, are given implicitly by the pair of equations:

$$
\begin{aligned}
p^{a}(\theta) & =\frac{\alpha}{1-\alpha} \frac{2-\theta(1+c)}{2 \theta-\frac{\theta^{2}}{2}} \\
\theta\left(p^{a}\right) & =\min \left\{1, \max \left[0,2-\frac{\beta+c}{\beta p^{a}}\right]\right\} .
\end{aligned}
$$

Where the first expression is derived from the market clearing condition, ${ }^{35}$ and the second equation pins down the equilibrium skill composition according to (2.8) and under the boundary conditions that by definition $0 \leq \theta \leq 1$. Solving yields the parametric form of

\footnotetext{
${ }^{35}$ i.e. $q^{s}\left(p^{a}\right)=d^{s}\left(p^{a}\right) \Rightarrow q^{s}\left(\theta\left(p^{a}\right)\right)=\frac{\alpha}{p^{a}}\left[p^{a} q^{s}\left(\theta\left(p^{a}\right)\right)+q^{u}\left(\theta\left(p^{a}\right)\right)\right] \Rightarrow p^{a}=\frac{\alpha}{1-\alpha} \frac{q^{s}\left(\theta\left(p^{a}\right)\right)}{q^{u}\left(\theta\left(p^{a}\right)\right)}$.
} 
the (interior) autarkic price:

$$
p^{a}=\frac{\alpha \beta c+\sqrt{((1-\alpha) c+\beta(1+\alpha(1+c)))^{2}-2 \alpha \beta((1-\alpha) c+\beta(1+\alpha(1+2 c)))}}{2(1-\alpha) \beta} .
$$

Notice that the Cobb-Douglas preference structure (with $\alpha \in(0,1)$ ) ensures that the economy will be diversified in autarky. Thus, we know that $\theta\left(p^{a}\right)>0$ so that the lower boundary condition on $\theta$ will not bind. It is possible, however, to reach a corner solution in which $\theta\left(p^{a}\right)=1$; even if every agent is skilled in the second period of life, the young generation will produce a positive quantity of the unskilled good as long as $c<1$. The corner solution at $\theta\left(p^{a}\right)=1$ will obtain if $\frac{\alpha}{1-\alpha} \geq \frac{3}{2} \frac{\beta+c}{\beta(1-c)}$; that is, every worker will upgrade her skills under autarky for sufficiently high values of $\alpha$ (strong preference for the skill-based good) or $\beta$ (a low discount rate). Conversely, the boundary condition is certain not to bind in the limit as $c \rightarrow 1$.

\section{A2 Tariff Revenue}

This appendix investigates how the paper's results are affected by the collection and redistribution of tariff revenue. As is customary in the literature, we assume that in each period tariff revenue is distributed uniformly among the members of the population. Denoting the aggregate tariff revenue at time $t$ by $R_{t}$, this implies that each agent alive at time $t$ receives a allocation of $r_{t}=R_{t} / 2$.

It is clear that uniform redistribution of tariff revenue will not affect individuals' skill acquisition decisions. To see this, note that equation (2.2) has to be augmented with the inclusion of tariff revenue as follows:

$$
v\left(p_{t}, 1-c+r_{t}\right)+\beta v\left(p_{t+1},(1+a) p_{t+1}+r_{t+1}\right) \geq v\left(p_{t}, 1+r_{t}\right)+\beta v\left(p_{t+1}, 1+r_{t+1}\right) .
$$

Evaluating the inequality, the tariff revenue payments cancel immediately, since the marginal utility of income is constant under Cobb-Douglas preferences. Thus, we have that every agents' skill acquisition decision- and hence the identity of the median voter- is independent of the (uniform) tariff revenue rebate, $r_{t}$. 
The tariff revenue rebate clearly does carry important implications for individuals' preferences over trade policy, as the payment generally will vary with the tariff. We can solve the modified model to generate the following expression for the per capita tariff rebate as a function of the ad-valorem tariff and skill composition of the population:

$$
r_{t}=\frac{1}{2}\left(\tau_{t}-1\right) \frac{\alpha c \theta_{t}+\left(2(1-\alpha) \frac{p^{w}}{\tau_{t}}+\alpha\right) \theta_{t-1}-\frac{1}{2}(1-\alpha) \theta_{t-1}^{2} \frac{p^{w}}{\tau_{t}}-2 \alpha}{1-(1-\alpha)\left(\tau_{t}-1\right)}
$$

Tautologically, tariff revenue is zero under a free trade regime $(\tau=1)$. Likewise, as the tariff approaches the prohibitive level, tariff revenue must again fall back to zero. But within the intermediate range of positive, non-prohibitive tariffs, revenue is a positive and concave function of the tariff: starting from free trade, revenue at first increases with the tariff until the revenue maximizing tariff is reached, and then revenue falls with the tariff approaching the prohibitive level.

Returning to our main analysis, a choice between any two tariff regimes entails a change in tariff revenue that can be positive, negative, or possibly zero. This revenue effect will in general change the identity of the indifferent voter, although it does not affect the identities of the respective median voters as noted earlier.

Consider, for illustration, a case in which tariff revenue is lower for $\tau_{L}$ than for $\tau_{P} .{ }^{36}$ The loss in tariff revenue that accompanies liberalization (or the forgone increase in revenue from maintained liberalism) - which we did not consider in the main text - makes $\tau_{L}$ somewhat less attractive relative to $\tau_{P}$ and therefore increases the ability level of the indifferent voter relative to the case in which tariff revenue is discarded. This rightward shift in $\tilde{a}$ may jeopardize the political stability of the liberal regime while strengthening the stability of the more protectionist tariff. And indeed, if both tariff regimes constituted political steady states when ignoring tariff revenue, it is possible that uniform redistribution of the collected tariff receipts could completely undercut the political stability of the liberal regime so that the $\tau_{P}$ would constitute the unique political steady state.

In sum, while the redistribution of tariff revenue in general will influence the identity of the indifferent voter within the population and thus the potential multiplicity of political

\footnotetext{
${ }^{36}$ Normative economics would suggest that this case is the more relevant, in which liberalization brings a concomitant loss in tariff revenue. Note that the opposite case is simply the mirror image.
} 
steady states given any set of exogenous parameter values, it does not change the qualitative conclusions of the main text. 